\title{
NOVEL LEAD ZIRCONATE TITANATE COMPOSITE VIA FREEZING TECHNOLOGY FOR HIGH FREQUENCY TRANSDUCER APPLICATIONS
}

\author{
B. P. ZHU, Q. F. ZHOU*, C. H. HU and K. K. SHUNG \\ NIH Transducer Resource Center and Department of Biomedical Engineering \\ University of Southern California \\ Los Angeles, California 90089-1111, USA \\ *qifazhou@usc.edu \\ E. P. GORZKOWSKI and M. J. PAN \\ Naval Research Laboratory \\ Code 6351, 4555 Overlook Ave SW \\ Washington, DC 20375, USA
}

Received 23 August 2010

Revised 26 September 2010

\begin{abstract}
Novel PZT-5A ceramic-polymer composite was prepared via freezing technology. This composite exhibited good dielectric and ferroelectric behaviors. At $1 \mathrm{kHz}$, the dielectric constant and the dielectric loss were 546 and 0.046 , respectively, while the remnant polarization was $13.0 \mu \mathrm{C} / \mathrm{cm}^{2}$ at room temperature. The electromechanical coupling coefficient $\left(k_{t}\right)$ of PZT-5A composite was measured to be 0.54 , which is similar to that of PZT piezoelectric ceramic. The piezoelectric coefficient $\left(d_{33}\right)$ of PZT-5A composite was determined to be $\sim 250 \mathrm{pC} / \mathrm{N}$. Using this composite, a $58 \mathrm{MHz}$ single element transducer with the bandwidth of $70 \%$ at $-6 \mathrm{~dB}$ was built, and the insertion loss was tested to be $-29 \mathrm{~dB}$ around the central frequency.
\end{abstract}

Keywords: Piezoelectric composite; PZT; transducer.

\section{Introduction}

Unlike X-ray imaging, ultrasound is safer for human tissue, so ultrasound imaging is now among the most commonly used medical imaging techniques. The desire to use ultrasound imaging to examine the eye, skin and blood vessels has driven the ultrasound frequency higher and higher.

Nowadays, lead-based piezoelectric material lead zirconate titanate (PZT) crystalline ceramic has been extensively studied for ultrasound transducer

\footnotetext{
${ }^{*}$ Corresponding author.
}

applications on medical imaging, due to its high piezoelectric performance. As we all know, the relatively high acoustic impedance of PZT (approximately 30 MRayls) causes a problem of acoustic impedance mismatch with the human tissue (1.5 MRayls) to be probed, which could substantially reduce the amount of ultrasound energy being transmitted into the tissue and result in lower sensitivity for ultrasound imaging. Therefore, elaborate acoustic matching layer with the thickness of 
quarter wavelength which could improve the overall performance of ultrasound transducer including sensitivity and bandwidth has been developed. ${ }^{1}$ Nevertheless, this technology could be not suitable for high frequency transducer $(>50 \mathrm{MHz})$ fabrication, because it is extremely difficult for using conventional lapping technology to control the matching layer's thickness which is required to be only several micrometers.

One promising way to overcome this difficulty is to combine piezoelectric material with a passive polymer to form piezoelectric material-polymer composite which has not only the high electromechanical coupling and suitable dielectric constant but also the low acoustic impedance. In addition, unlike traditional piezoelectric ceramic and single crystal, this kind of composite is not brittle so crack formation could be avoided during lapping down process. In prior researches, several methods ${ }^{2-8}$ have been utilized to synthesize piezoelectric materialpolymer composites in different phase conductivity. However, none of those composites has been used for high frequency $(>50 \mathrm{MHz})$ applications. Recently, Deville et al. ${ }^{9}$ has published a paper in Science and suggested that freezing is a path to build complex composites. The natural principle applied is that the various impurities originally present in sea water (silt, biological organisms, etc.) are expelled from the forming ice and entrapped within channels between the ice crystals when pure hexagonal ice platelets with randomly oriented horizontal c crystallographic axes are formed in sea ice. This ideal fabrication process is simple and adaptable enough to synthesize layers with a large number of material combinations and a wide range of layer dimensions. Therefore, it is worthy to study whether piezoelectric material-polymer aligned composite prepared by freezing technology is suitable for high frequency $(>50 \mathrm{MHz})$ ultrasound transducer application or not.

\section{Experimental}

In this experiment, ceramic slurry was prepared by mixing purified water with $2 \mathrm{wt} \%$ of the ammonium polymethacrylate dispersant, Darvan C, (R. T. Vanderbilt Co., Norwalk, CT), 1 wt\% of polyvinyl alcohol (Alfa Aesar, Ward Hill, MA), and PZT-5A ceramic powder (Morgan Electroceramics, Bedford, $\mathrm{OH}$ ) in optimum proportion. Slurry was ball-milled in a high density polyethylene bottle for $12 \mathrm{~h}$ with zirconia milling media and de-aired in a vacuum desiccator. Freezing of the slurry was accomplished by pouring them into a Teflon mold (diameter: $3.8 \mathrm{~cm}$, height: $1.9 \mathrm{~cm}$ ) and cooled using a custom built freezing setup. The mold was placed between two copper rods that were cooled by liquid nitrogen. There were band heaters attached to the copper rods in order to control the cooling rate and temperature gradient. The samples were freeze-dried (Freeze Dryer 2.5, Labconco, Kansas City, MO) for $24 \mathrm{~h}$, and then were removed from the mold for annealing. Binder burnout and bisque firing were done by heating the samples in several steps: $1.2^{\circ} \mathrm{C} / \mathrm{min}$ to $300^{\circ} \mathrm{C}, 0.1^{\circ} \mathrm{C} / \mathrm{min}$ to $350^{\circ} \mathrm{C}, 0.6^{\circ} \mathrm{C} / \min$ to $500^{\circ} \mathrm{C}$, $5^{\circ} \mathrm{C} / \mathrm{min}$ to $900^{\circ} \mathrm{C}$, and finally, a $1 \mathrm{~h}$ dwell at $900^{\circ} \mathrm{C}$. The samples were sintered at $1150^{\circ} \mathrm{C}$ for $2 \mathrm{~h}$. Each cylindrical sample was then infiltrated with Epotek 301 Epoxy (Epoxy Technology, Billerica, MA) under vacuum.

The morphology of the composite was monitored by a scanning electron microscope (SEM; Hitachi, S-3500N, Tokyo, Japan). The dielectric permittivity, dielectric loss and electric impedance were measured using an impedance analyzer (HP4194A, Hewlett-Packard). High field hysteresis property was characterized using an RT6000 (Radiant Technology, Albuquerque, NM) ferroelectric test system with a voltage amplifier. The $d_{33}$ measurement was performed on the PZT-5A aligned composite sample using a Berlincourt piezo $d_{33}$ meter (Channel Products INC., Hesterland, $\mathrm{OH}$ ) after being poled at $60^{\circ} \mathrm{C}$ for $5 \mathrm{~min}$ at $50 \mathrm{kV} / \mathrm{cm}$.

\section{Result and Discussion}

Figure 1 shows the SEM microstructure image of PZT-5A sintered sample. It can be found that the sample consists of aligned PZT-5A ceramic lamellae which contain considerable porosity. The alignment of the ceramic lamellae is in the direction of the temperature gradient and the porosity is probably caused by the sample shrinking in the sintering process. It is worth noting that the platelets are not exactly parallel to the temperature gradient. This is most likely due to the differences between the imposed and the preferred growth directions. The preferred growth direction is controlled by the system, i.e., interfacial energies while the imposed growth direction is highly dependent on the temperature gradient. ${ }^{10,11}$ Low-temperature gradient could make the preferred growth direction dominate 


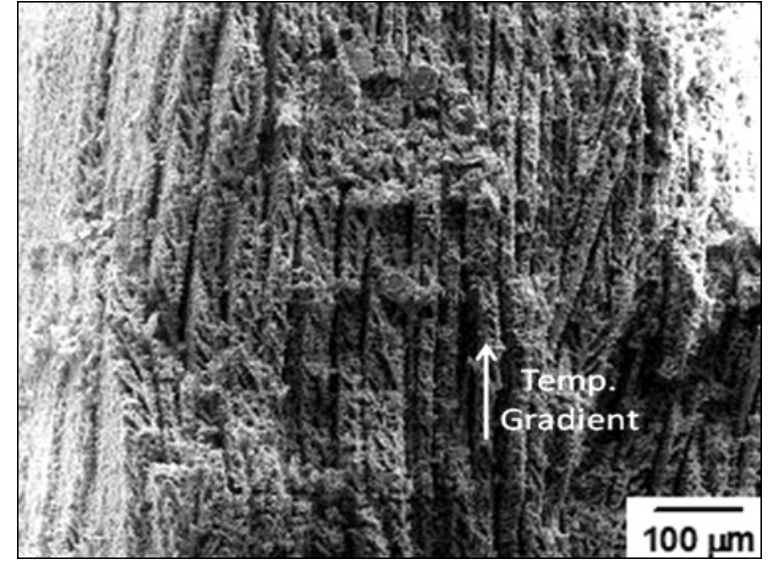

Fig. 1. SEM image of the microstructure of freeze-cast PZT$5 \mathrm{~A}$ aligned composite sample.

and cause the platelets grow a few degrees off the temperature gradient direction. In order to modify the platelets' parallel configuration, a larger temperature gradient should be used in future experiment.

As shown in Fig. 2, the dielectric constant of the PZT-5A aligned composite sample decreases with the frequency increasing in the frequency range from $1 \mathrm{kHz}$ to $1 \mathrm{MHz}$. At $1 \mathrm{kHz}$, the value of the dielectric constant is 546. The dielectric constant of the material which consists of two phase connected in parallel can be given by the equation below:

$$
\varepsilon=\varepsilon_{\mathrm{PZT}} V_{\mathrm{PZT}}+\varepsilon_{\text {polymer }} V_{\text {polymer }},
$$

where $\varepsilon_{\mathrm{PZT}}=1741^{12}$ is the dielectric constant of PZT-5A ceramic and $\varepsilon_{\text {polymer }}=15$ is the dielectric constant of Epoxy 301; $V_{\mathrm{PZT}}$ and $V_{\text {polymer }}$ denote the

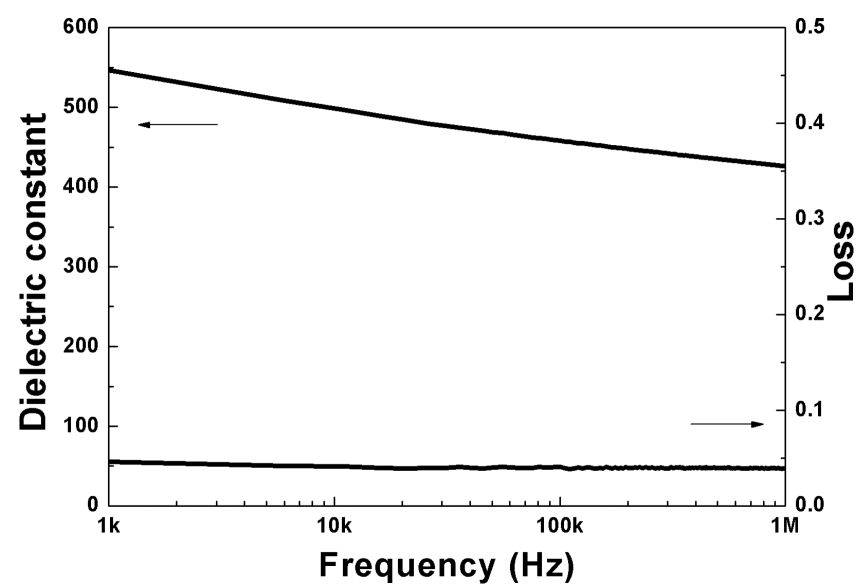

Fig. 2. Frequency dependence of dielectric constant and loss of the PZT-5A aligned composite sample. volume ratios of PZT-5A and Epoxy 301 in the composite, respectively. Moreover, the mathematic relationship of $V_{\text {PZT }}$ and $V_{\text {polymer }}$ can be described as the following expression:

$$
V_{\mathrm{PZT}}+V_{\text {polymer }}=1 \text {. }
$$

Through simultaneous Eqs. (1) and (2), the PZT-5A volume ratio $\left(V_{\mathrm{PZT}}\right)$ can be calculated to be $30.8 \%$. For optimum efficiency in ultrasound imaging transducer, the volume fraction of ceramic in the composite should be maintained in the range of $20-30 \mathrm{vol} \% .^{8}$ The experimental result is very close to the desired value. Additionally the dielectric loss of the PZT-5A aligned composite sample, decreasing from 0.046 to 0.038 , varies slightly in the frequency range from $1 \mathrm{kHz}$ to $1 \mathrm{MHz}$. The dielectric loss is almost two times as much as that of PZT-5A ceramic (about 0.02), which is likely due to the pores in the platelets, but the loss is still low enough for device application.

Figure 3 shows the polarization-electric field hysteresis loop of the PZT-5A aligned composite sample. The sample exhibits ferroelectric behavior with a good symmetry loop as would be expected. It can be seen that the coercive field $\left(E_{\mathrm{c}}\right)$, remnant polarization $\left(P_{\mathrm{r}}\right)$, and saturation polarization $\left(P_{\mathrm{s}}\right)$, are $14 \mathrm{kV} / \mathrm{cm}, 13 \mu \mathrm{C} / \mathrm{cm}^{2}, 17 \mu \mathrm{C} / \mathrm{cm}^{2}$, respectively.

Figure 4 represents the electric impedance versus frequency for PZT-5A aligned composite sample poled with the electric field of $50 \mathrm{kV} / \mathrm{cm}$ at $60^{\circ} \mathrm{C}$. It demonstrates experimentally that the resonant frequency is $f_{\mathrm{r}}=4.45 \mathrm{MHz}$ and the anti-resonant

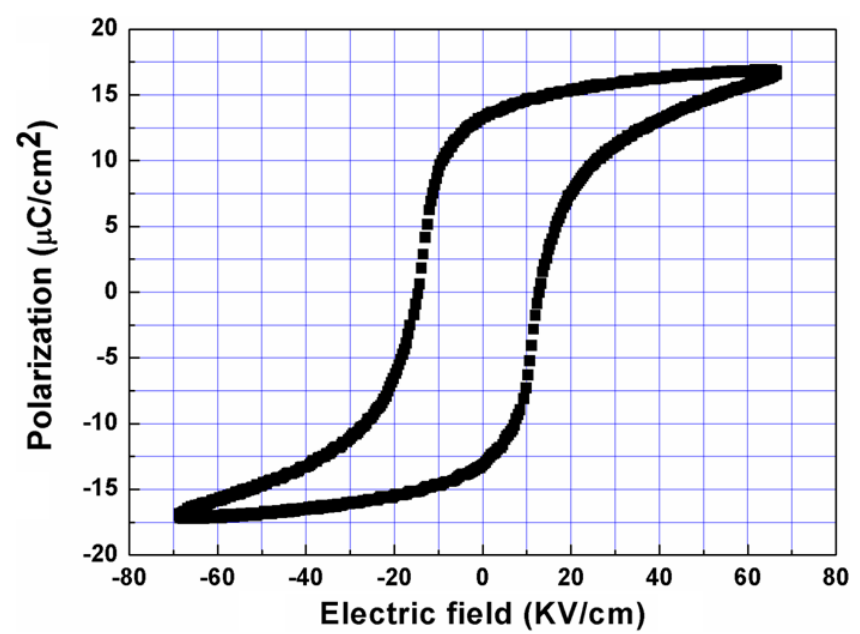

Fig. 3. Polarization-electric field hysteresis loop and the PZT-5A aligned composite sample. 


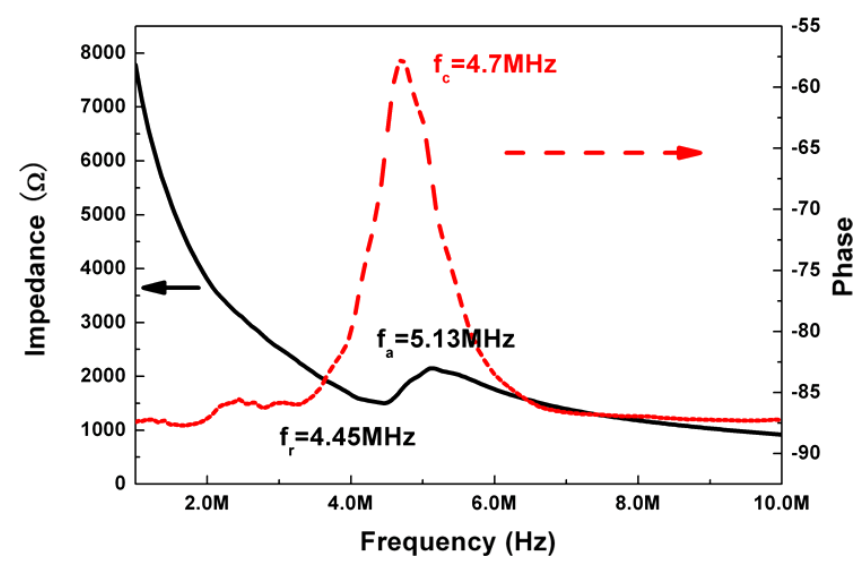

Fig. 4. The electric impedance versus frequency for PZT-5A aligned composite sample poled with the electric field of $50 \mathrm{kV} / \mathrm{cm}$ at $60^{\circ} \mathrm{C}$.

frequency is $f_{\mathrm{a}}=5.13 \mathrm{MHz}$. The electromechanical coupling coefficient $k_{t}$ of this composite could be evaluated from the following formula ${ }^{13}$ :

$$
k_{t}^{2}=\frac{\pi}{2} \frac{f_{\mathrm{r}}}{f_{\mathrm{a}}} \tan \left(\frac{\pi}{2} \frac{f_{\mathrm{a}}-f_{\mathrm{r}}}{f_{\mathrm{a}}}\right) .
$$

After substituting the values of $f_{\mathrm{r}}$ and $f_{\mathrm{a}}$ into Eq. (3), $k_{t}$ can be calculated to be 0.54 , which is superior to that of piezoelectric PZT-5A ceramic $\left(k_{\mathrm{t}}=0.5\right)$. The thickness $(t)$ of the PZT-5A aligned composite sample is $300 \mu \mathrm{m}$ and the central frequency $\left(f_{\mathrm{c}}\right)$ shown in Fig. 4 is $4.7 \mathrm{MHz}$, so the sound propagation speed $(c)$ in this kind of material can be obtained: $c=2 f_{\mathrm{c}} t=2820 \mathrm{~m} / \mathrm{s}$. Meanwhile, the density of PZT-5A aligned composite sample was measured to be $3000 \mathrm{~g} / \mathrm{cm}^{3}$ using Archimedes method. Therefore, the acoustic impedance of this composite can be determined to be $Z=c \rho=8.46$ MRayls, which is much closer to that of human tissue in contrast to acoustic impedance of piezoelectric PZT-5A ceramic (about 30 MRayls). Additionally, the piezoelectric coefficient $d_{33}$ of PZT-5A composite was tested to be $\sim 250 \mathrm{pC} / \mathrm{N}$.

After the PZT-5A aligned composite sample was lapped down to $25 \mu \mathrm{m}$. A conductive backing material, E-solder 3022 (VonRoll Isola, New Haven, $\mathrm{CT}$ ), was cured over the opposite side of the composite and lapped to under $3 \mathrm{~mm}$. Active element plug was diced out at $0.65 \mathrm{~mm}$ aperture and housed using Epoxy 301 (Epoxy Technology Inc., Billerica, MA) once an electrical connector was fixed to the conductive backing using a conductive epoxy. An electrode was sputtered across the composite face and the housing to form the ground plane connec-

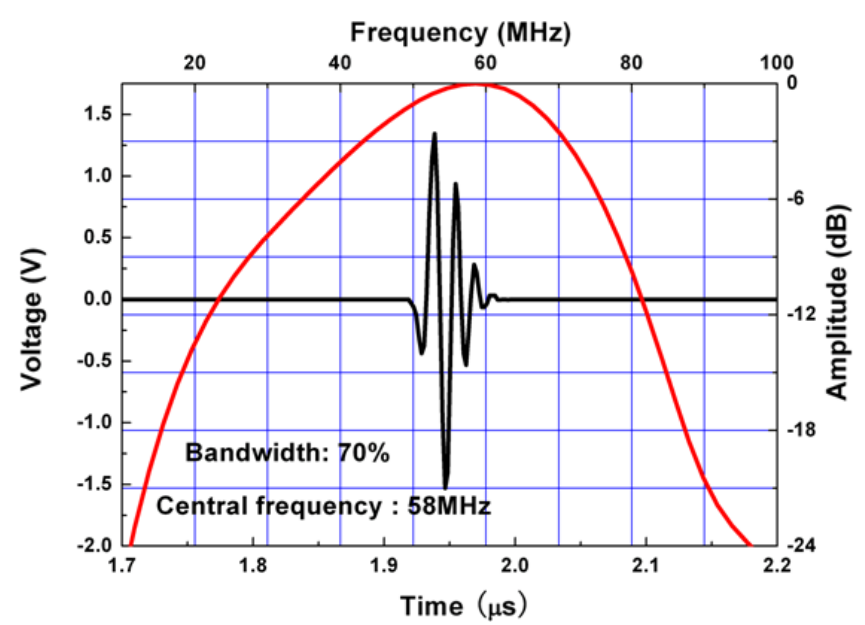

Fig. 5. Pulse echo response and the spectrum of PZT-5A aligned composite single element transducer.

tion. The transducer was tested in deionized water bath in pulse/echo mode by reflecting the signal off an X-cut quartz target. For pulse/echo measurements, transducer excitation was achieved with a Panametrics (Waltham, MA) model 5900 Pr pulser/ receiver. The reflected waveform was received and digitized by a $500 \mathrm{MHz}$ LC 534 Lecroy (Chestnut Ridge, NY) oscilloscopes. Figure 5 shows a pulse echo waveform and the normalized frequency spectrum of the PZT-5A aligned composite single element transducer. The center frequency of the transducer is $58 \mathrm{MHz}$ and the bandwidth at $-6 \mathrm{~dB}$ is around $70 \%$. Insertion loss was measured using several cycle sinusoid pulse produced using a Sony/ Tetronix (Beaverton, OR) model AFG2020 arbitrary function generator. At $58 \mathrm{MHz}$, the insertion loss was measured to be $-29 \mathrm{~dB}$.

\section{Conclusion}

In summary, a novel freezing technology was introduced to prepare piezoelectric material-polymer aligned composite material. Results showed that aligned composite sample had suitable dielectric constant, low dielectric loss, good ferroelectric property and very low acoustic impedance. A high frequency single element acoustic transducer built with PZT-5A aligned composite showed a bandwidth at $-6 \mathrm{~dB}$ of $70 \%$ and insertion loss of $-29 \mathrm{~dB}$ at $58 \mathrm{MHz}$, indicating that freeze casting method is a promising way to fabricate piezoelectric composite for high frequency transducer application. 


\section{Acknowledgement}

This work has been partially supported by $\mathrm{NIH}$ grant \# P41-EB2182.

\section{References}

1. K. K. Shung and M. Zipparo, IEEE Eng. Med. Biol. Mag. 15, 20 (1996).

2. Z. Xu, F. T. Chen, Z. Z. Xi, Z. Li, L. H. Cao, Y. J. Feng and X. Yao, Ceram. Inter. 30, 1777 (2004).

3. C. P. Chong, H. L. Li, H. L. W. Chan and P. C. K. Liu, Ceram. Inter. 30, 1141 (2004)

4. L. J. Bowen, R. L. Gentilman, H. T. Pham, D. F. Fiore and K. W. French, Ultrasonics Symposium 1, 499 (1993).

5. R. K. Panda, S. C. Danforth and A. Safari, J. Mater. Sci. Lett. 17, 1395 (1999).

6. S. A. Wilson, G. M. Maistron and R. W. Whatmore, J. Phys. D: Appl. Phys. 38, 175 (2005).
7. S. Schwarzer and A. Roosen, J. Euro. Ceram. Soc. 19, 1007 (1999).

8. G. M. Lous, I. A. Cornnejo, T. F. Mcnulty, A. Safari and S. C. Danforth, J. Am. Ceram. Soc. 83, 124 (2000).

9. S. Deville, E. Saiz, R. Nalla and A. Tomsia, Science 311, 515 (2006).

10. S. Deville, E. Saiz and A. Tomsia, Acta Materialia 55, 1965 (2007).

11. G. W. Young, S. H. Davis and K. J. Brattkus, J. Cryst. Growth 83, 560 (1987).

12. M. D. Durruthy-Rodríguez, A. Jiménez-Cañas, O. Sánchez-Casals, L. D. Pérez-Fernández, A. PeláizBarranco, F. Calderón-Piñary and L. Leija-Salas. Rev. Cub. Física 23, 62 (2006).

13. Q. F. Zhou, X. C. Xu, E. Gottlieb, L. Sun, J. Cannata, H. Ameri, M. Humayun, P. D. Han and K. K. Shung, IEEE Trans. Ultrason. Ferroelect. Freq. Contr. 54, 668 (2007). 